\title{
Placement and Sizing of Distributed Generation on Distribution Systems with a Multi-Objective Particle Swarm Optimization and Analytical Approach: A Review
}

\author{
Pooja Shivwanshi \\ Radharaman Engineering College, \\ Bhopal, M.P. India
}

\author{
Sameena Elias Mubeen \\ Radharaman Engineering College, \\ Bhopal, M.P. India
}

\begin{abstract}
The Distributed generations (DGs) have number of benefits in the electric power industry, such as improvement of voltage stability, enhancement of reliability and power quality. This paper compares the DG placement result of analytical approach with the Multi-Objective Particle Swarm Optimization (MOPSO). The analytical method is based on a formulation for the power flow problem. A priority is loss sensitivity to determine the best locations of applicant distributed generation units. The multi-objective particle swarm optimization determines the optimal DGs places and sizes. The MOPSO improves voltage profile and stability, power-loss reduction, and reliability enhancement. The results show that the analytical method could lead to optimal or nearoptimal result, while requiring lower computational effort.
\end{abstract}

\section{Keywords}

DG placement, DG sizing, distributed generation, Analytical optimization method, multiobjective particle swarm optimization (MOPSO).

\section{INTRODUCTION}

The Distribution generation systems are the requirement of the time and the energy management system. The advantages of DGs are eco-friendly-ness, improvement in the voltage profile and reduced power losses. Distribution systems are characterized by high $\mathrm{R} / \mathrm{X}$ branch ratios with radial or weakly-meshed topological arrangement [1-4]. The radial topological structure makes distribution systems the most extensive part in the entire power system.

The DG unit is a PV bus on a radial distribution feeder. It implies that on-line systems including DG-units can be more reliable interruption situations to keep customers supplied. It states that the simplest representation of DG-units operating in parallel with the system, especially in radial feeders, is as negative active and reactive power injections, independent of the system voltage at the terminal bus. When using multiple DG-units as PV configurations, it is unrealistic to manage these DG-units as available for dispatching because they may not be controlled by the utility. The optimal output is impacted by the social economic and political factors. For maximizing the load supply, costs reduction and operational schedules by exploiting evolutionary programming (EP) for all feeder loads level. On the basis of maximum cost reduction, the optimal solution can be selected by evaluating the cost of DG-unit supply circumstances based on the base case in figure [5] a method to calculate the optimal DG-unit size is described. The advantages are maximized by using the best suitable location and size of the DGs in the power system through various computational techniques as PSO, analytical technique [3] etc.
The particle swarm optimization technique (PSOT) and multiobjective PSOT and are applying the heuristic approaches and get the result of the optimum position size. The detailed analysis is done in the second section. The analytical approach comprise the basic steps as the development of a liberalized power flow model, in which the coupling between active power and voltage magnitude as well as the coupling between reactive power and voltage angle is maintained. The detailed analysis is done in the third section. The Distributed generations (DGs) [6-8] have number of benefits in the electric power industry, such as improvement of voltage stability, enhancement of reliability and power quality [9-11].

The remainder of the paper is organized as follows. Section II presents the mathematical formulations of the problem in MOPSO, Section III explains the MOPSO approach. Next section VI explains the analytical approach, Section V includes results and discussion, and Section V outlines the conclusions.

\section{BASIC MODEL OF OBJECTIVE FUNCTIONS}

The loss minimization is the basic objective of the system with the DG placement. The formulation of the loss calculation is described below:

$$
P_{L}=\sum_{i=1}^{N} \sum_{j=1}^{N}\left[\alpha\left(P_{i} P_{j}+Q_{i} Q_{j}\right)+\beta_{i j}\left(P_{i} P_{j}+Q_{i} Q_{j}\right)\right]
$$

Where

$\alpha_{i j}=\frac{r_{i j}}{V_{i} V_{j}} \cos \left(\delta_{i}-\delta_{j}\right) ; \beta_{i j}=\frac{r_{i j}}{V_{i} V_{j}} \sin \left(\delta_{i}-\delta_{j}\right)$

$V_{i} \angle \delta_{i}$ ith bus voltage in complex form

$r_{i j}+j x_{i j}=Z_{i j}$ ijth element of [Zbus] impedance matrix;

$P_{i}$ and $Q_{j}$ reactive power injection at the ith and jth buses, respectively; $\mathrm{N}$ number of buses

The optimal size of DG at each bus $i$ for the minimum loss given by reducing (2)

$$
P_{D G i}=P_{D i}-\frac{1}{\alpha_{i i}} \sum_{\substack{j=1 \\ j \neq i}}^{N}\left(\alpha_{i j} P_{j}-\beta_{i j} Q_{j}\right)
$$




\subsection{Bus Voltages and Branch Currents Limits}

These limitations are defined as follows:

$$
\begin{gathered}
\mathrm{I}_{\mathrm{b}, \mathrm{t}, \mathrm{j}} \leq \mathrm{I}_{\mathrm{b}}^{\max } \\
\mathrm{V}^{\min } \leq \mathrm{V}_{\mathrm{n}, \mathrm{t}, \mathrm{j}} \leq \mathrm{V}^{\max }
\end{gathered}
$$

Where $\mathrm{v}^{\min }$ and $\mathrm{v}^{\max }$ are the minimum and maximum allowed amounts of voltage in each bus, respectively. Also denotes the maximum amount of current that can flow in each line according to the lines thermal limitations.

\subsection{DG Capacity Limit}

It should be assumed that the active and reactive capacity of each DG is limited to a specific interval as follows:

$$
\begin{aligned}
& P_{D G}^{\min } \leq P_{D G, i} \leq P_{D G, i}^{\max } \\
& Q_{D G}^{\min } \leq Q_{D G, i} \leq Q_{D G, i}^{\max }
\end{aligned}
$$

In these inequalities, $P_{D G, i}^{\min }, P_{D G i}^{\max }, Q_{D G, i}^{\min }$ and $Q_{D G, i}^{\max }$ are the minimum and maximum amounts of active and reactive powers that can be generated by the ith DG unit.

\section{MULTI OBJECTIVE PARTICLE SWARM OPTIMIZATION (MOPSO)}

The appropriate DG size calculation with minimum loss is considered as the single objective of the method. The DG size approximation with appropriate DG location also getting the suitable voltage profile with minimum loss is the motive main of the multi-objective method. That can be obtained through the MOPSO method with suitable variable allocation. The flowchart of the MOPSO method is shown in figure 1.

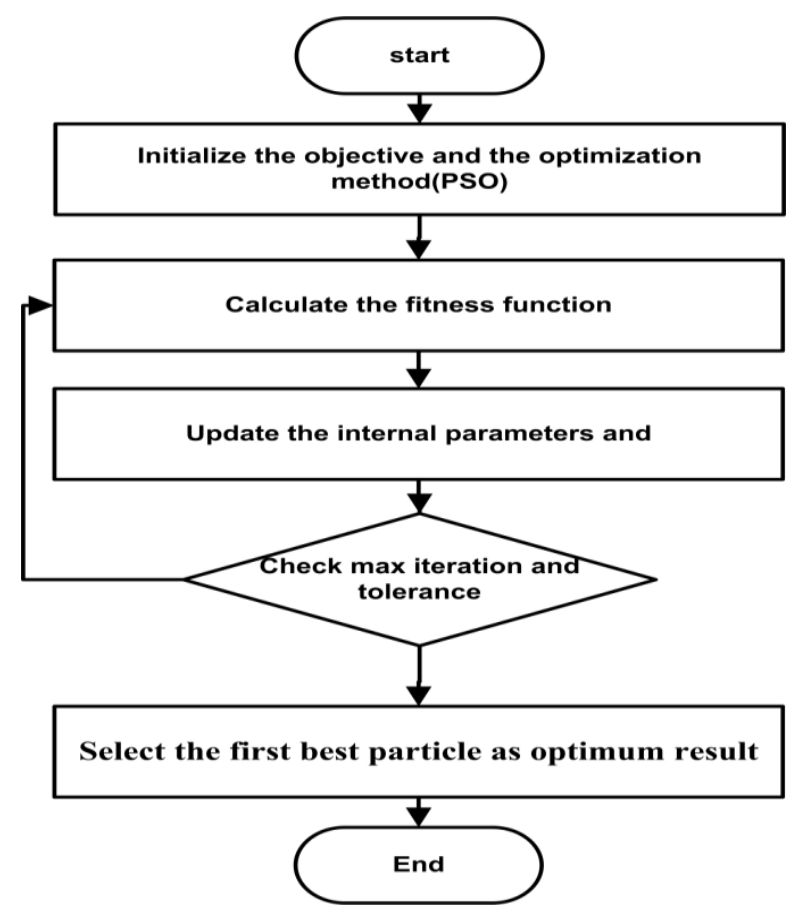

Fig 1. Flowchart of the multi-objective PSO method

The MOPSO is suitable in case of minimizing multiple objective functions simultaneously. If $\mathrm{f}(\mathrm{x})$ consists of an objective functions, then the multiobjective problem can be defined as finding the vector $x^{*}=\left[x_{1}^{*}, x_{2}^{*} \ldots x_{m}^{*}\right]$ in order to minimize $\mathrm{f}(\mathrm{x}) \operatorname{minf}(x)=\left\langle f_{1}(x) f_{2}(x) \ldots f_{n}(x)\right\rangle$ subject to $x^{*} \in \chi[12,14]$. In the minimization problem, the solution $\mathrm{x} 1$ dominates $\mathrm{x} 2$ if

$$
\text { 1) } \forall_{i} \in\left\{1,2, \ldots N_{o b j}\right\}: f_{i}\left(x_{1}\right) \leq f_{i}\left(x_{2}\right)
$$

Like PSO, in the MOPSO algorithm, each particle at the time $\mathrm{t}$ is introduced by two borders, its velocity $V_{i}(t)$ and its position $X_{i}(t)$. According to following equations, each vector will be updated at time $(\mathrm{t}+1)$ as below [12]

$$
\begin{gathered}
V_{i}(t+1)=w(t) V_{i}(t)+c_{1} r_{1}\left(L_{i}(t)-X_{i}(t)\right)+c_{2} r_{2}\left(G_{i}(t)\right. \\
\left.\quad-X_{i}(t)\right) \\
X_{i}(t+1)=V_{i}(t)+X_{i}(t)
\end{gathered}
$$

Where $c 1$ and $c 2$ are positive constant coefficients which show the importance of local best and global best, respectively, $r 1$ and $r 2$ and are random numbers. $w(t)$ is inertia weight which helps the algorithm to find the Pareto optimal set more rapidly and is almost always constant. $L_{i}(t)$ and $G_{i}(t)$ are local best and global.

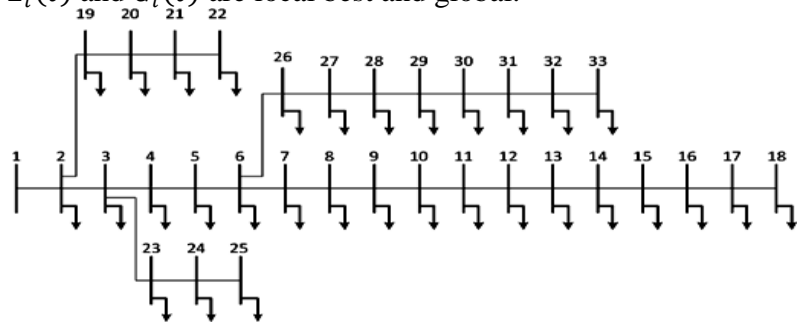

Fig 2: IEEE 33-bus distribution test system

The MOPSO is applied with the above mentioned objective function, the constraints and the basic PSO parameters c1, c2, $\mathrm{w} 1$, and w2 with initial random position in the defined range on the 33 bus system. The single line diagram of the 33 bus system is shown in figure 2 . The computed results are discussed in the section five.

\section{ANALYTICAL APPROACH}

The analytical approach $[3,13]$ basically provides the suitable solution on the basis of the analysis of the formulation of the model not on the repetitive solution of the model. More than one objective can also be taken care of by relating these formulas. The flowchart of the analytical method is shown in figure 3.

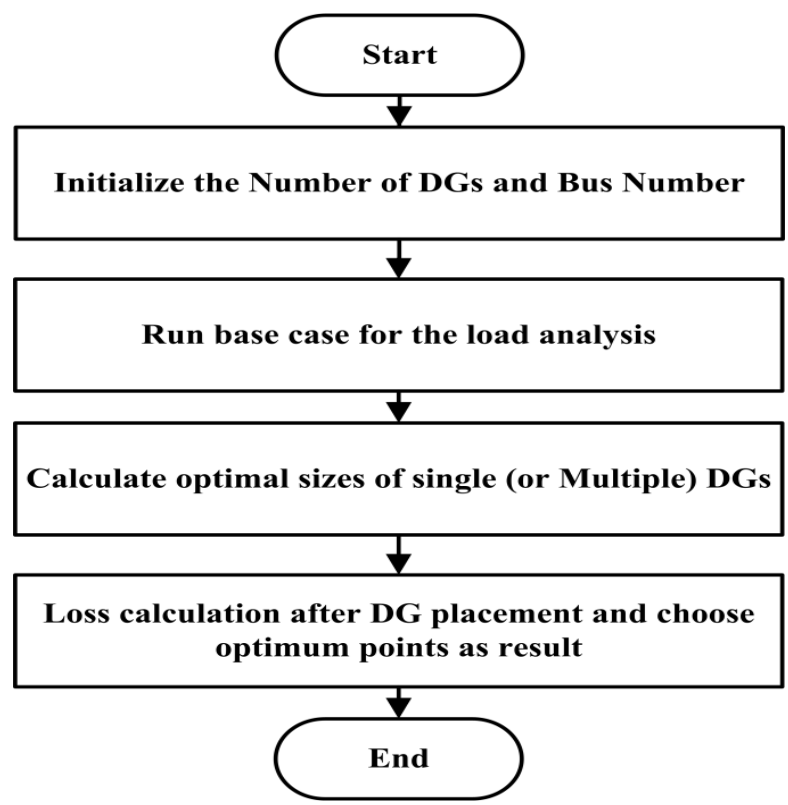

Fig 3. Flowchart of the Analytical method 
The buses are ranked in descending order of the values of their sensitivity factors to form a priority list. The basic objective function of the method is to minimize the real power loss and getting better the voltage profile at all system buses with sensitivity consideration. The sensitivity factor of real power loss with respect to real power injection from DG is given by

$$
\alpha_{i}=\frac{\partial P_{L}}{\partial P_{i}}
$$

Sensitivity factors are evaluated at each bus, firstly using the values obtained from the base case power flow. The total power loss calculation is done by using the relation (2). The Real and reactive power injections on the specific bus is related as

$$
\begin{aligned}
& B^{\prime} \delta-G V+P_{G}=P_{D} \\
& G^{\prime} \delta-B V+Q_{G}=Q_{D}
\end{aligned}
$$

In the above formulation (11) the sum of the power at any arbitrary bus is simply the power balance equation for real and reactive power. The implementation of the analytical approach for the fulfillment of above mentioned objective function considering the sensitivity as another parameter for the balancing of the DG size and location with minimum loss.

\section{RESULTS AND DISCUSSION}

The MOPSO and the analytical approach are implemented on the platform of MATLAB 2012a with the i5 processor $2.20 \mathrm{GHz}$ frequency and 4 GB RAM. The voltage profile and the power loss variations are calculated. The voltage profile for 33 bus system is shown in figure 4 with bus to bus voltage variation.

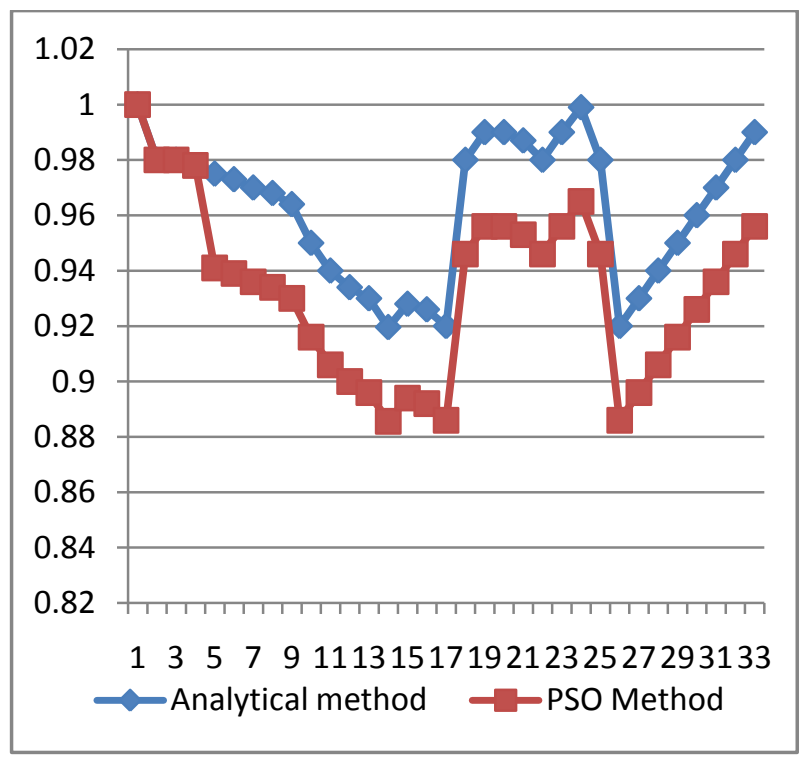

Fig. 4 Voltage profile of the 33-bus system obtained MOPSO and analytical methods

The comparison of voltage variation and power loss for the MOPSO and the analytical method are shown in table 1. These parameters are extreme points in the computation results of the simulation.
Table:1 Result comparison for 33 bus system DG placed at position 14

\begin{tabular}{|c|c|c|}
\hline Method & $\begin{array}{c}\text { Voltage } \\
\text { Deviation }\end{array}$ & $\begin{array}{c}\text { Power } \\
\text { Loss(Kv) }\end{array}$ \\
\hline MOPSO & 0.1104 & 92.06 \\
\hline $\begin{array}{c}\text { Analytical } \\
\text { Approach }\end{array}$ & 0.0812 & 79.40 \\
\hline
\end{tabular}

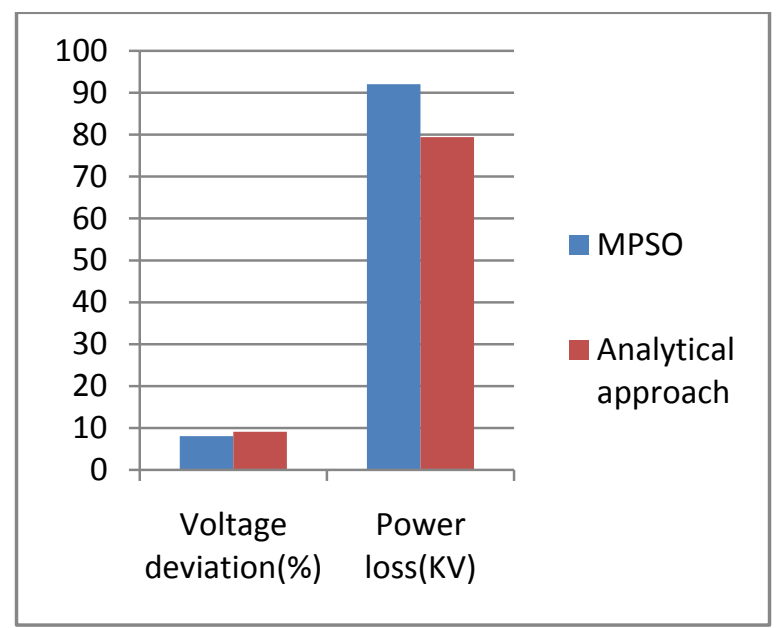

Fig.5. Graph represents the voltage deviation and power loss of MPOS and analytical approach

\section{CONCLUSION}

In this paper, the MOPSO algorithm and analytical approach has been used to find the optimal solution of DGs sizing and locating problems. Moreover, the given approaches are to obtain the best solution considering power-loss reduction, voltage profile. The analytical algorithm results show that approx. 15\% less power loss as compared to the MOPSO approach. The voltage profile of the analytical approach is showing close to unity as compared to the MOPSO approach. There is the scope to work on the hybrid optimization techniques with various load flow schemes.

\section{REFERENCES}

[1] D. Q. Hung, N. Mithulananthan, and R. C. Bansal, "Analytical Expressions for DG Allocation in Primary Distribution Networks," IEEE Trans. on Energy Conversion, vol. 25, no. 3, Sept. 2010, pp. 814-820.

[2] S. Civanlar, J. J. Grainger, H. Yin, and S. S. H. Lee, "Distribution feeder reconfiguration for loss reduction," IEEE Trans. Power Del., vol. 3, no. 3, pp. 1217-1223, Jul. 1988 .

[3] N. Acharya, P. Mahat, and N. Mithulananthan, "An analytical approach for DG allocation in primary distribution network," Int. J. Electr. Power Energy Syst., vol. 28, no. 10, pp. 669-678, 2006.

[4] M. El-Arini and A. Fathy, "An Efficient and reliable method for optimal allocating of the distributed generation based on optimal teaching learning algorithm," WSEAS Trans. on Power Systems, vol. 10, 2015, pp. 188-197.

[5] S. Kansal, V. Kumar, and B. Tyagi, "Hybrid Approach for Placement of Type-III Multiple DGs in Distribution Network," J. Electrical \& Electronic Systems, 2014, $3: 130$ 
[6] R. Rao, K. Ravindra, K. Satish, S. Narasimham, 'Power loss minimization in distribution system using network reconfiguration in the presence of distributed generation', IEEE Trans. Power Syst., 2012, 28, (1), pp. $1-9$

[7] T. Ackermann, G. Andersson, L. Soder, "Distributed generation: a definition," Electr. Power Syst. Res., 2001, 57, pp. 195-204

[8] W. Caisheng and M. H. Nehrir, "Analytical approaches for optimal placement of distributed generation sources in power systems," IEEE Trans. Power Syst., vol. 19, no. 4, pp. 2068-2076, Nov. 2004.

[9] M. A. Kashem, A. D. T. Le, M. Negnevitsky, and G. Ledwich, "Distributed generation for minimization of power losses in distribution systems," presented at the Power Energy Soc. Gen. Meeting Conf., Montreal, QC, Canada, 2006.

[10] T. Ackermann, G. Anderson, and L. S. Soder, "Distributed generation: Adefinition," Elect. Power Syst. Res., vol. 57, no. 3, pp. 195-204, 2011.
[11] M.M. Aman, G. B. Jasmon, H. Mokhlis, and A. H. A. Bakar, "Optimal placement and sizing of a DG based on a new power stability index and line losses," Int. J. Elect. Power Energy Syst., vol. 43, no. 1, pp. 1296-1304, 2012.

[12] M. H. Moradi and M. Abedini, "A combination of genetic algorithm and particle swarm optimization for optimal DG location and sizing in distribution systems," Int. J. Elect. Power Energy Syst., vol. 34, no. 7, pp. 6674, 2006.

[13] S. Elsaiah, M. Benidris, J. Mitra, "Analytical approach for placement and sizing of distributed generation on distribution systems,"IET Gener. Transm. Distrib., 2014, Vol. 8, Iss. 6, pp. 1039-1049

[14] A. Ameli, S. Bahrami, F. Khazaeli and M.-Reza Haghifam, "A Multiobjective Particle Swarm Optimization for Sizing and Placement of DGs from DG Owner's and Distribution Company's Viewpoints" IEEE Trans. on Power Delivery, vol. 29, no. 4, Aug. 2014. 